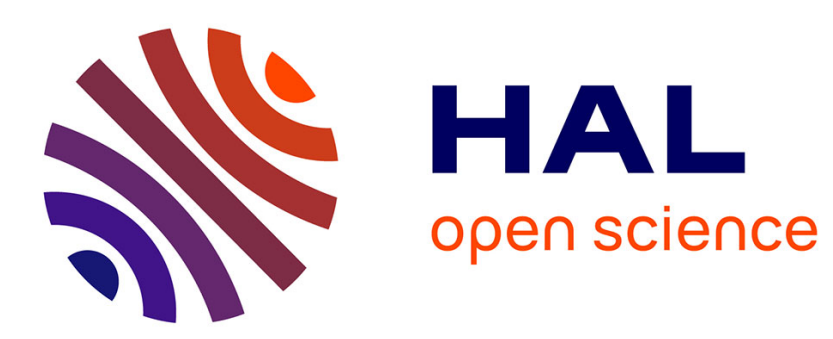

\title{
Ductile Fracture of Pure Copper: An Experimental and Numerical Study
}

\author{
M. Mirza, D. Barton, P. Church, J. Sturges
}

\section{To cite this version:}

M. Mirza, D. Barton, P. Church, J. Sturges. Ductile Fracture of Pure Copper: An Experimental and Numerical Study. Journal de Physique IV Proceedings, 1997, 07 (C3), pp.C3-891-C3-896. 10.1051/jp4:19973150 . jpa-00255439

\section{HAL Id: jpa-00255439 https://hal.science/jpa-00255439}

Submitted on 1 Jan 1997

HAL is a multi-disciplinary open access archive for the deposit and dissemination of scientific research documents, whether they are published or not. The documents may come from teaching and research institutions in France or abroad, or from public or private research centers.
L'archive ouverte pluridisciplinaire HAL, est destinée au dépôt et à la diffusion de documents scientifiques de niveau recherche, publiés ou non, émanant des établissements d'enseignement et de recherche français ou étrangers, des laboratoires publics ou privés. 


\title{
Ductile Fracture of Pure Copper: An Experimental and Numerical Study
}

\author{
M.S. Mirza, D.C. Barton, P. Church* and J.L. Sturges** \\ Department of Mechanical Engineering, University of Leeds, LS2 9JT, U.K. \\ * DERA, Fort Halstead, Sevenoaks, Kent TN14 7BP, U.K. \\ ** Department of Construction, Metropolitan University of Leeds, LS2 8BU, U.K.
}

\begin{abstract}
This paper describes the results of interrupted tensile tests carried out on $99.95 \%$ pure copper specimens over a range of stress triaxiality conditions. The tested specimens were sectioned and polished to identify the conditions at which voids nucleate and coalesce before the final fracture takes place. Results show that void nucleation and coalescence both have a very strong dependence on stress triaxiality, but appear to be less sensitive to strain-rate. Based on the combined experimental and numerical results, a new criterion for void nucleation is proposed as a function of stress triaxiality.
\end{abstract}

Résumé. Cet article présente les résultats d' essais de traction interrompus obtenus sur des échantillons de cuirve à $\mathbf{9 9 . 9 5 \% ~ p u r ~ d a n s ~ d e s ~ c o n d i t i o n s ~ d e ~ c o n t r a i n t e s ~ t r i a x i a l e s . ~ L e s ~ e ́ c h a n t i l l o u s ~ t e s t e ́ s ~ o u t ~ e ́ t e ́ ~ s e c t i o n n e ́ s ~ e t ~ p o l i s ~ a f i n ~ d ' ~}$ identifier les conditions de nucléation et de coalescence des vides avant que n'intervienne la rupture finale. Les résultats montrent que la nucléation et la coalescence des vides sont fortement dépendantes de la triaxialité des coutraintes; mais sout moins sensibles aux taux de cisaillement. Basé sur la combinaison de résultats numériques et expérimentaux, un nouveau critère de nucléation des vides est proposé eu taut que fonction de la triaxialité des contraintes.

\section{INTRODUCTION}

The uniaxial tensile test using solid cylindrical tension specimens has been widely used to characterise the complete ductile fracture process in metals. The final ductile fracture in a tensile specimen is a result of a sequence of processes: (a) homogeneous deformation; (b) incipient necking; (c) nucleation of voids; (d) coalescence of voids; (e) crack formation; (f) shear deformation. Puttick[1] and Bluhm \& Morrissey[2] were among the first to identify the different stages of ductile fracture by performing controlled interrupted tensile experiments. Different stages of ductile fracture were also identified by LeRoy et al[3] for various carbon steels. These investigations have led to a better understanding of the basic micromechanics of the ductile fracture process. Most of these studies, however, have been carried out on standard tensile specimens with uniform gauge length whereas it is well known that ductile fracture in metals is strongly dependent on the state of triaxial stress as shown by McClintock[4], Rice \& Tracey[5] and Hancock \& Mackenzie[6]. This paper presents results of controlled interrupted tests carried out on pure copper at quasi-static and intermediate rates over a range of triaxial stress states, in order to investigate the effect of stress state on the various stages of the ductile fracture.

The experimental studies have not only led to a better understanding of the basic fracture process but have also been used to develop quantitative theoretical models to represent the different phases of the process, though a comprehensive theory which can represent the complete process remains elusive. The Tvergaard-Needleman-Gurson void nucleation and growth model [7] has been widely employed to predict the ductile fracture. The rate of nucleation of voids in the model is controlled by

$$
\dot{f}_{\text {nucleation }}=A \dot{\epsilon}^{P}
$$

where

$$
A=\frac{f_{N}}{S_{N} \sqrt{2 \pi}} \exp \left[-\frac{1}{2}\left(\frac{\epsilon^{P}-\epsilon_{N}}{S_{N}}\right)\right]
$$


The terms $f_{N}$ and $S_{N}$ are the volume fraction and standard deviation of the void nucleating particles. $\varepsilon^{\mathrm{P}}$ is the local plastic strain and $\varepsilon_{\mathrm{N}}$ is the mean strain at which voids nucleate. This nucleation criterion. suggested by $\mathrm{Chu} \&$ Needleman[8], does not take into account the effect of stress triaxiality on void nucleation. In the second part of this paper, it is shown that the nucleation strain does in fact have a strong dependence on stress triaxiality and a new criterion for the nucleation of voids as a function of stress triaxiality is proposed.

\section{EXPERIMENTAL PROGRAMME}

\subsection{Material and Specimen Details}

The material used in this test programme is Oxygen Free High Conductivity (OFHC) copper of purity $99.95 \%$ conforming to BS2874 C103. The micro-structure of the undeformed material is shown in Figure 1. The average grain size is about $35 \mu \mathrm{m}$.

A total of five different specimen geometries were used to obtain a range of stress triaxiality conditions. Two plain specimens with gauge diameters of $5 \mathrm{~mm} \& 7 \mathrm{~mm}$ and three notched specimens with notch profile radii of $4 \mathrm{~mm}, 2 \mathrm{~mm} \& 1 \mathrm{~mm}$ were machined from solid $\phi 12.5 \mathrm{~mm}$ bar, as shown in Figure 2

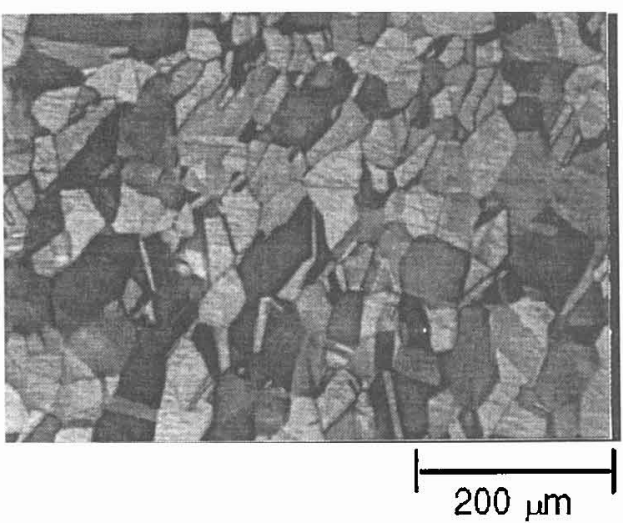

Figure 1. Grain Structure of OFHC copper.

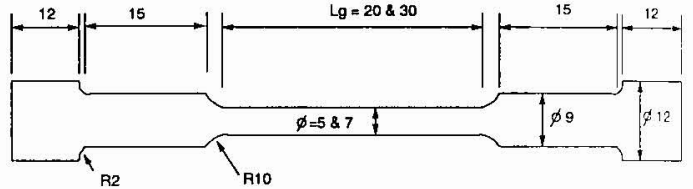

(a)

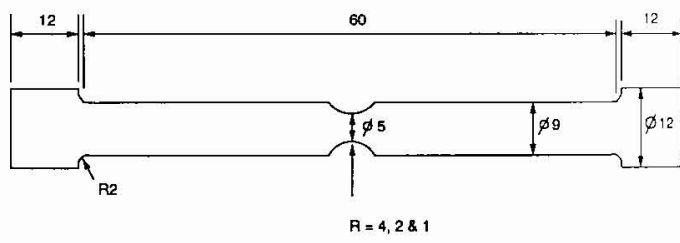

(b)

Figure 2. Details of specimen geometries used.

\subsection{Testing Procedure}

Tests were carried out on all five different types of specimens at a separation rate of $0.05 \mathrm{~mm} / \mathrm{s}$ using a computer-controlled servo-hydraulic universal testing machine. Tests were also conducted on $5 \mathrm{~mm}$ gauge diameter plain specimens at $5 \mathrm{~mm} / \mathrm{s}$ giving an average strain-rate of about $0.2 \mathrm{~s}^{-1}$. Change in the diameter of specimens during test was measured using a CCD video camera in conjunction with an image analysis system in order to precisely determine the true stress-strain curve. A typical stress-strain curve is shown in Figure $4 \mathrm{a}$. In order to isolate the different stages of the fracture process, specimens were subjected to different levels of strain without fracturing and the test interrupted. At least two specimens were tested to the same level of strain for each of the five different specimen types including testing two of each to complete fracture. The deformed specimens were sectioned in the longitudinal direction using a precision sectioning machine and subsequently ground and polished up to $0.05 \mu \mathrm{m}$ finish using standard metallographic techniques to reveal the exact centre plane to within $\pm 5 \mu \mathrm{m}$. Extreme care was takill throughout the polishing process so as not to induce artefacts onto the surface of the samples. 


\subsection{Experimental Results and Discussion}

Optical micrographs of the central region of polished $7 \mathrm{~mm}$ gauge diameter plain specimens at different stages of the fracture process are shown in Figure 3, along with the corresponding average plastic strain (defined as $\varepsilon=2 \ln \left(d_{d} / d\right)$ where $d_{o} \& d$ are the initial and current minimum diameters respectively). Different stages of the fracture are also identified on the true stress-strain curve and on the loaddisplacement curve shown in Figure 4 for this type of specimen. True stress is obtained by dividing the load by the minimum area at that instant. As can be seen from Figure 4, voids appears to nucleate at about $50 \%$ of the final strain to failure. Coalescence of these voids and formation of a micro-crack quickly follow without considerable further deformation and result in a marked change in slope or 'knee' in the load-displacement curve. Significant further reduction of area takes place after crack formation due to crack propagation and shear lip deformation leading eventually to final fracture of the specimen.

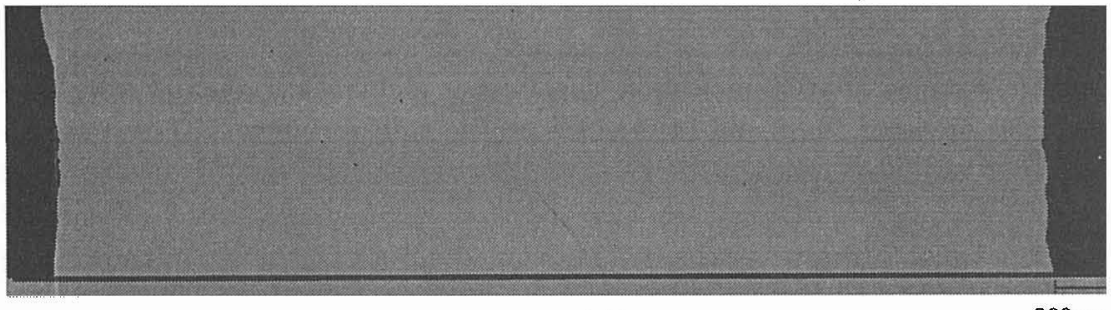

(a) $\varepsilon=1.21$

$200 \mu \mathrm{T}:$

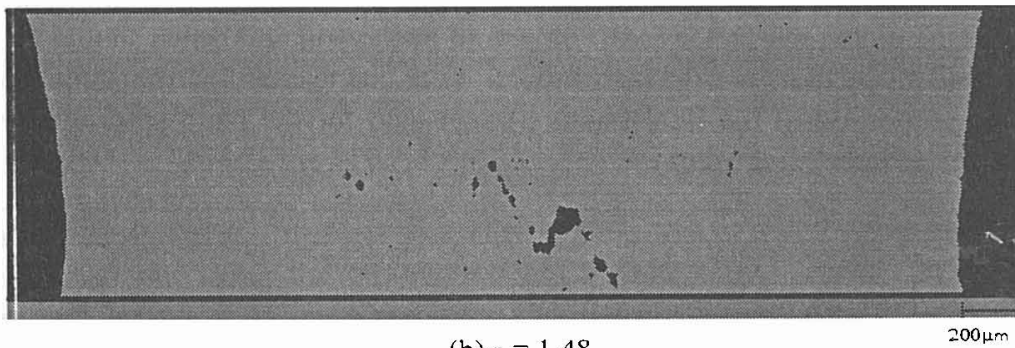

(b) $:=1.48$

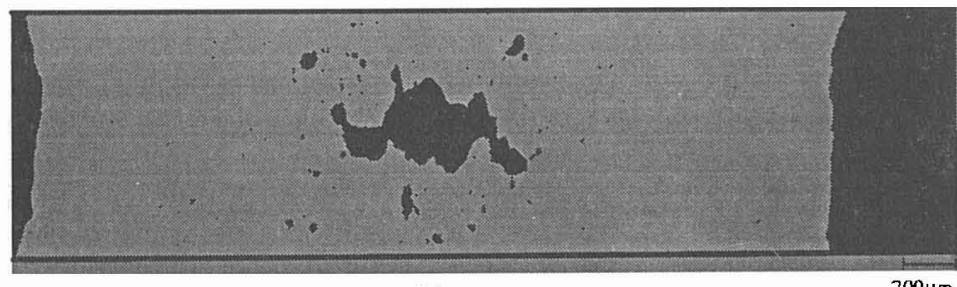

(c) $\varepsilon=1.55$

$200 \mu \mathrm{m}$

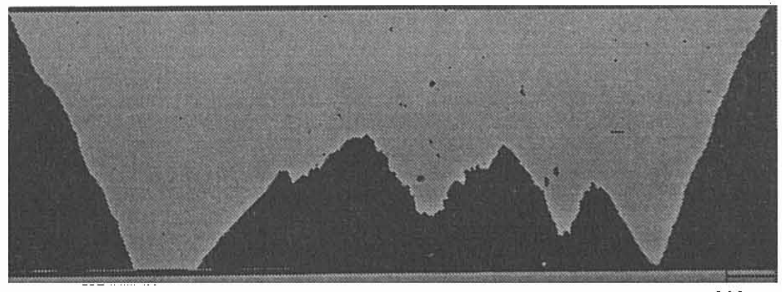

(d) $\varepsilon=2.47$

$200 \mu \mathrm{m}$

Figure 3. Optical micrographs of plain copper specimens illustrating: (a) void nucleation; (b) void coalescence; (c) crack formation; (d) final fracture. 


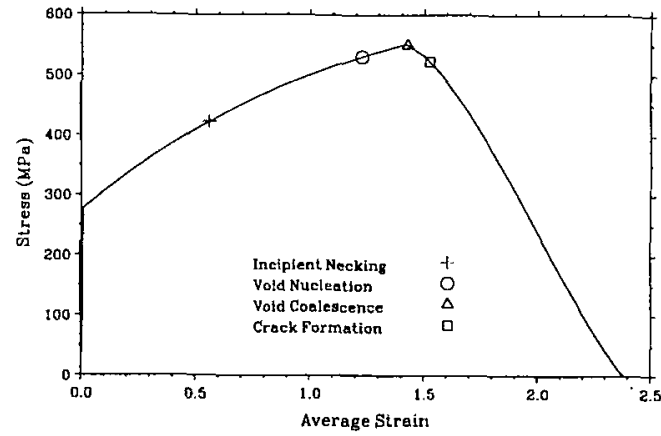

(a)

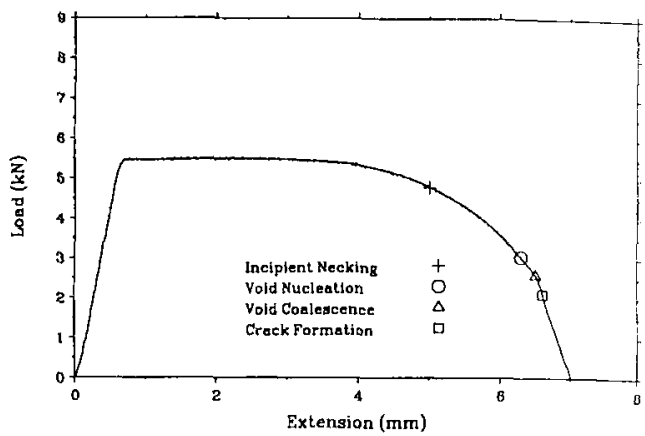

(b)

Figure 4. Results of interrupted tests on plain specimens: (a) true stress-strain curve; (b) load-displacement curve.

The different stages of void nucleation, coalescence and crack formation were also isolated from the interrupted tests on $4 \mathrm{~mm}, 2 \mathrm{~mm}$ and $1 \mathrm{~mm}$ notch profile radii specimens. These events are marked on the stress-strain curves shown in Figures 5-7 for the three notched specimens, respectively. Results of interrupted tests on all the different specimens are shown in Figure 8, in terms of the average plastic strain at nucleation, coalescence, crack formation and final fracture. It can be clearly seen from Figure 8 that the strain at the different stages of fracture decreases with decreasing notch profile radii i.e. with increasing stress triaxiality. It was also observed from the polished specimens that nucleation of voids always initiates near the central axis of the specimen where the stress triaxiality is maximum. This suggest that stress triaxiality is the governing factor controlling void nucleation and hence should be accounted for by any theoretical void nucleation and growth model. Void nucleation for the three notched specimens occurs at a lower proportion of the final fracture strain than for the plain specimen whilst coalescence again corresponds to a 'knee' in the curve.

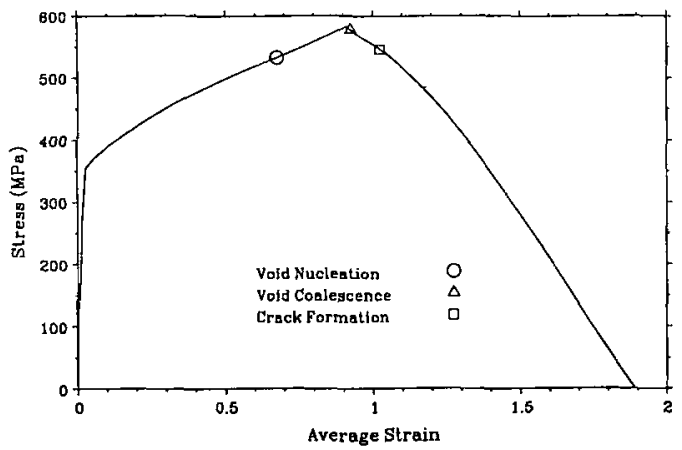

Figure 5. True stress-strain curve for $4 \mathrm{~mm}$ notched specimen

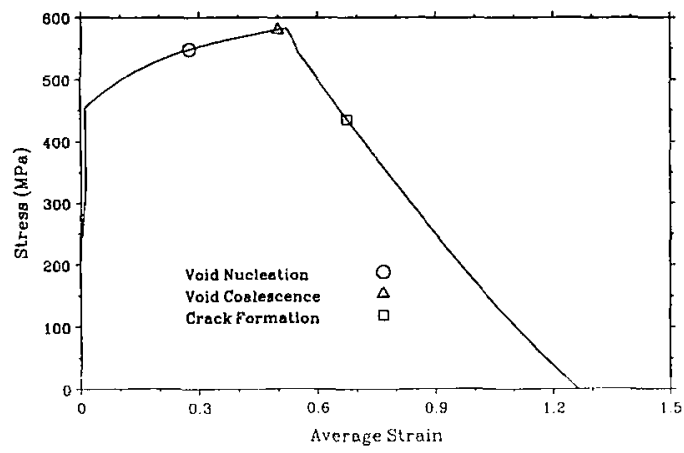

Figure 7. True stress-strain curve for $1 \mathrm{~mm}$ notched specimen

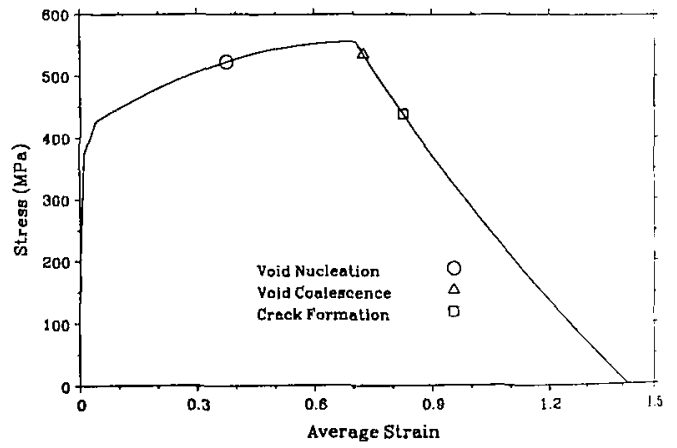

Figure 6. True stress-strain curve for $2 \mathrm{~mm}$ notched specimen.

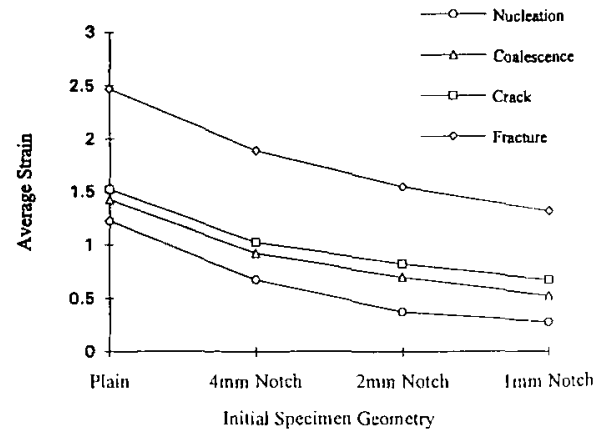

Figure 8. Average strain vs initial specimen geometry at different stages of ductile fracture. 
It has been shown that deformation and fracture of pure copper is generally independent of strainrate up to very high rates of the order of $10^{3} \mathrm{~s}^{-1}[9,10]$. Optical micrographs of interrupted tests carried out on plain specimens at intermediate strain-rates of about $0.2 \mathrm{~s}^{-1}$ in Figure 9 indicate that the nucleation and coalescence of voids occurs at the same average plastic strain as for the specimens tested quasi-statically. Conducting controlled interrupted test at very high strain-rates is of course not trivial, especially for the notched specimen where complete fracture takes place with just a few millimetres of extension. These initial results, however, suggest that the fracture processes of void nucleation and coalescence are independent of strain-rate.

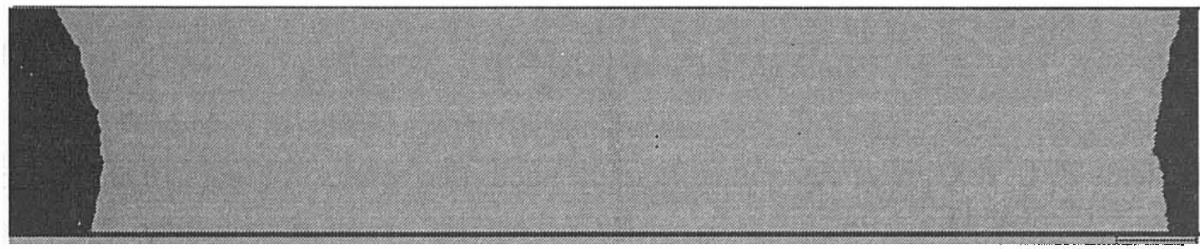

(a) $\varepsilon=1.20$

$200 \mu \mathrm{m}$

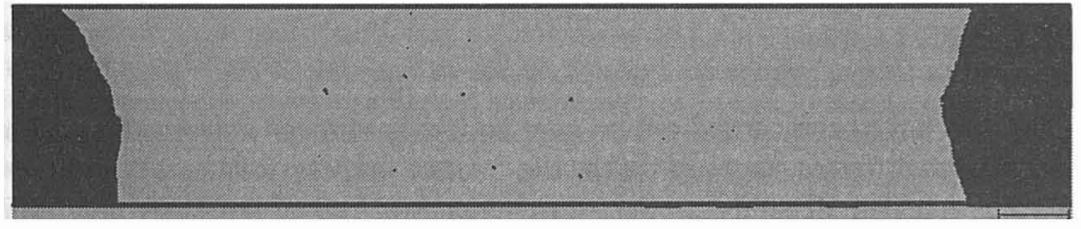

(b) $\varepsilon=1.38$

$200 \mu \mathrm{m}$

Figure 9. Optical micrographs of tests at intermediate separation rates;(a) void nucleation; (b) just before void coalescence.

\section{NUMERICAL MODELLING OF FRACTURE}

In order to obtain realistic estimates of stress triaxiality at the centre of a deforming specimen, numerical simulations were carried out using the NIKE2D implicit finite element code for the three notched geometries as well as for the plain specimen. The Zerilli-Armstrong constitutive relation for OFHC copper [11] was used without a fracture model for the material response. The purpose of this was to determine local values of stress and strain at the centre of the neck in order to quantify the effect of stress triaxiality on the different stages of the fracture process. The numerical simulations yielded values of the stress triaxiality parameter, defined as the ratio of mean stress $\left(\sigma_{m}\right)$ to von Mises effective stress $\left(\sigma_{e}\right)$, and local plastic strain at the centre of the specimen corresponding to the measured average plastic strain at void nucleation. Plots of NIKE2D predicted values of local plastic strain at nucleation against the stress

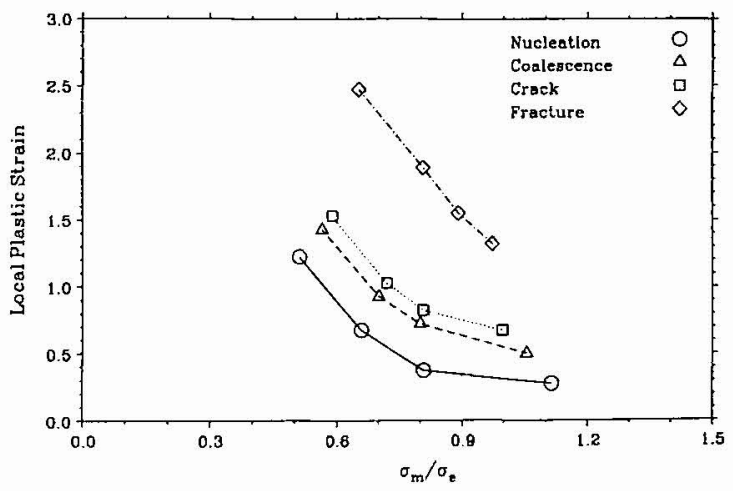

Figure 10. Predicted local plastic strain against stress triaxiality factor at different stages of ductile fracture. 
triaxiality parameter are shown in Figure 10 for all the different specimen geometries tested. Curves corresponding to void coalescence, crack formation and complete fracture are also shown in Figure 10, but numerical predictions after void nucleation should be treated as only crude estimates as the simulations do not account for the presence of voids and their growth.

It is apparent from the nucleation curve of Figure 10 that the strain at which voids nucleate $\left(\varepsilon_{\mathrm{N}}\right)$ varies non-linearly with stress triaxiality. This is in contrast to the assumption in the TvergaardNeedleman-Gurson nucleation model described in Section 1 that the nucleation strain is constant. Hence the strain at void nucleation could be represented as a function of stress triaxiality by the relation :

$$
\epsilon_{N}=C_{1}+C_{2} \exp \left(C_{3} \frac{\sigma_{m}}{\sigma_{e}}\right)
$$

Best fit constants $\mathrm{C}_{1} \mathrm{C}_{2} \& \mathrm{C}_{3}$ were determined from the nucleation results of Figure 10 and found to be: $\mathrm{C}_{1}=0.09, \mathrm{C}_{2}=19.98$ and $\mathrm{C}_{3}=5.54$.

\section{CONCLUSIONS}

Interrupted tensile tests have been carried out on pure copper specimens over a range of stress triaxiality conditions to identify the different stages of the ductile fracture process. Results of the study show that the strain at which voids nucleate depends strongly on the state of triaxial stress. A new criterion for void nucleation as a function of stress triaxiality has been developed.

\section{Acknowledgements}

This work was carried out under the UK Defence Evaluation and Research Agency agreement number WSS/U1091 for which support the authors are duly grateful. The authors are also thankful to Lawerence Livermore National Laboratory, USA, for providing NIKE2D and related software.

\section{References}

[1] Puttick K.E., Phil. Mag. 5(1960) 759-762.

[2] Bluhm J.I. and Morrissey R.J., Proc. 1st Int. Conf. Fract. 3(1966) 1739-1780.

[3] LeRoy G., Embury J.D., Edwards G. and Ashby M.F., Acta Metall 29(1981) 1509-1522.

[4] McClintock F.A, J. Appl. Mech. 35(1968) 363-371.

[5] Rice J.R. and Tracey D.M., J. Mech. Phys. Solids. 17(1969) 201-217.

[6] Hancock J.W. and Mackenzie A.C., J. Mech. Phys. Solids. 24(1976) 147-169.

[7] Tvergaard V. and Needleman A., J. Mech. Phys. Solids. 32(1984) 461-490.

[8] Chu C.C. and Needleman A., J. Engng. Mat. Tech. 102(1980) 249-256.

[9] Parry D.J. and Walker A.G., "Effects of grain size and temperature on mechanical properties of OFHC copper", Proceedings of the 4th International conference on the Mechanical Properties of Materials at High Rates of Strain, Oxford 19-22 March 1989, Harding J. Eds. pp. 329-336.

[10] Lassila D.H., "Effects of grain size and strain rate on the mechanical response of OFHC copper", Proceedings of the 4th International conference on the Mechanical Properties of Materials at High Rates of Strain, Oxford 19-22 March 1989, Harding J. Eds. pp. 323-327.

[11] Zerilli F.J. and Armstrong R.W., J. Appl. Phys.,61(1987) 1816-1825. 